\title{
The chasmed gene
}

\author{
Diddahally R. Govindaraju $u^{1,2^{*}}$ (D)
}

\section{Book details}

Mukherjee, S. The Gene: An intimate history.Scribner, NY.594 pages; ISBN: 978-1-4767-330-0; Price: \$20.00.

"...genes should not be spoken of as valuable without defining what they are valuable for."-Wright (1931) (Provine 1986).

“...gene action is not a final term. The gene is primarily called into play at a particular time and place by conditions external to it."-Wright (1934a).

"...organisms are the nexus of a very large number of weakly determining causal forms, and are subjected to stochastic uncertainty. What is true for organism at one time may not be true for others at other times and in other circumstances."-Lewontin (2001).

The Industrial Revolution led to increased population growth, greater demand for food production and a quest for understanding the workings of nature. Amateur plant and animal breeders and horticulturists have exploited natural variation for centuries in order to boost food production and to meet other societal needs. Some of these investigators working primarily in Europe also realized the importance of a systematic understanding of plant and animal biology, including reproductive mechanisms, with a view to preserve the purity of varieties and breeds and to exploit hybrid vigor and principles underlying the expression of these traits. Three scientists -Darwin, Wallace and Mendel-tower over them. Darwin and Wallace are well known for recognizing the force of nature acting upon variation, through their theory (law) of natural selection. As most of us know, Darwin, in addition to being influenced by Malthus and Lyell, borrowed ideas freely from plant and animal breeders and applied them to develop his theory. He also explored modes of plant and animal reproduction, physiology, inheritance and

\footnotetext{
${ }^{*}$ Correspondence: dgovindaraju@fas.harvard.edu

${ }^{1}$ Department of Human Evolutionary Biology, Harvard University, 11 Divinity Avenue, Cambridge, MA 02130, USA

Full list of author information is available at the end of the article
}

variation, in his treatise, "The Variation of Animals and Plants Under Domestication."

Mendel, on the other hand, discovered the fundamental principles of inheritance and distribution of variation which eluded Darwin. Contrary to Darwin-Wallace's law of natural selection, which made an instant impact toward understanding the nature and distribution of biological diversity, Mendelian laws were brought to light in 1900-nearly four decades after their original discovery. However, the application of Mendelian principles to elucidate the action of natural selection on all living systems was swift, following Bateson, who also proposed the term "Genetics" as "the elucidation of the phenomenon of heredity and variation." Subsequent discoveries in the 11 decades since have illuminated that the law of natural selection and the laws of inheritance both complement and converge. It is hard to believe that ideas on inheritance and variation, big and small, that took roots among Europe's scattered farms and arboreta have crept into halls of medical schools and the Wall Street alike, and are shaping human health. They are also a favorite subject for Nobel Prizes!

In his book, "The Gene: An intimate history" Dr. Siddhartha Mukherjee, has undertaken the formidable task of presenting a "historical" perspective of genetics in six parts, covering about 600 pages, largely from a human health and disease view point. The book has a prologue and an epilogue about the health of his own family and a philosophical reflection on "Bheda" and "Abheda"divisibility and indivisibility, respectively and their plausible consequences on the genetic system. He clearly states his objective on page 12: "Embedded in the history of the gene (emphasis mine) is the 'the quest for eternal youth, the Faustian myth of abrupt reversal of fortune, and our own century's flirtation with the predictability of man.' Embedded equally, is the desire to decipher our 
manual of instructions. That is what is at the center of this story." It would not be a remiss to call this book a historical scientific novel on the reins of genes (genome) on human health and welfare and even perhaps destiny ("post-human"), as the author traces the history of genetics from Mendel's "Walled garden", to curing diseases attributable to genetic causes using "Genetic Therapies." His palpable honesty (mark of a good writer) about the health of his family members and their struggles with mental disorders resonates in some ways with the health of our own families, is at once painful and moving. The author is a gifted story-teller and his "novelist's" mind and pen glide freely across literary, scientific and medical landscapes.

Part one and two entitled, "Missing Science of Heredity" and "In the Sum of the Parts There are Only the Parts," respectively, have overlapping themes. The first part traces the history of genetics spanning 70 years from 1865 to 1935 . Here he presents Darwin's struggle to discover the "principle" responsible for maintaining inheritance and variation. Mendel subjected the data collected on qualitative and quantitative traits on individual crosses of peas and their filial generations of offspring to mathematical analysis. The general principles emerged from these studies later filled the void that eluded Darwin. Similarly, Galton's work "Hereditary Genius," published in 1869, and its subsequent influence both in Europe and in the US, in the name of eugenics are well presented. From a genetics perspective, Galton's other equally important work, "Natural Inheritance" (1889), is not discussed. In this book, Galton dealt with the resemblance of parents and offspring which stimulated some of the most enduring work in biometry, and paved the way toward a synthesis of Mendelian (genetics) and Darwinian (evolutionary) ideas or simply evolutionary genetics, particularly between 1910 and 1920. As opposed to "In the Sum of the Parts, There are Only the Parts," organisms are hierarchically organized and interacting systems of modular forms from molecules to populations. Therefore, "the whole is greater (could be lesser also) than the sum of its parts," as Aristotle has pointed out. Bold theoretical and experimental analysis were attempted to understand the inheritance, maintenance and distribution of genetic variation on wide ranging organisms. A synthesis of these findings took place between 1900 and 1930. This great body of work accomplished in a span of three decades amply supports the inadequacy of Cartesian-clock metaphor in genetics. But, a meager 17 or fewer pages are allotted to this body of research in evolutionary genetics in this 600-page tome! The author has provided a perfunctory view of the dynamic relationship among genotype-epigenetic (development)-phenotype spaces-through time and space (inheritance and maintenance of variation) by making broad generalizations ("Modern Synthesis or grandly, the Grand Synthesis"-Huxley 1942) about these processes. What is that synthesis and why is it "Grand"? Such gross imbalances are disconcerting, considering the fact that the author has allotted so much space to presenting trivial details about the idiosyncrasies of geneticists, molecular biologists and biotech gurus, alike. This is my major criticism about this book.

Let me illustrate only a few points and indicate what the readers-particularly those who are less familiar with the evolutionary aspects of genetics, might miss out, in this part of the book. Genetics by definition is the science of heredity and variation. While I appreciate the fact that the book is largely about human genetics and human health and disease, these concepts are buttressed by the rich experimental evidence drawn on other organismsviruses, bacteria, yeast, drosophila, corn, mice to name a few. Hence, it is impossible to present the work of great investigators spanning at least 115 years in this book devoted to the history of genetics. It is logical, however, to expect a reasonably balanced treatment of the topics covered. For instance, Garrod's work on biochemical disorders and Sutton and Bovery's theory on chromosomes as the carriers of hereditary units (later confirmed by Bridges), must appear upfront following the discovery of Mendelian principles because they bolstered Bateson's advocacy of Mendelism to support the Darwin-Wallace theory. Garrod's work influenced biochemistry, metabolic disorders and decades later, molecular genetics starting with Beadle and Tatum. Sutton and Bovery's theory on the other hand, was central to the discovery and mapping of genes by Morgan and others. Similarly, reference to Hardy-Castle-Weinberg law which laid the foundation for understanding the distribution and prediction of Mendelian variation is not found. The departure from Mendelian (simple) inheritance to more continuous (complex) variation by Nilson-Ehle which provided a genetic framework to interpret Galton's classic work on the distribution of human height and other quantitative traits (notably by Fisher) is not mentioned. Similarly, gene mapping by Morgan and his students and Muller's discovery of artificial induction of mutation is mentioned. But, parallel discoveries made on corn by Emerson and his students, are not. The role of genetic factors that modulate the "sum of the parts"-dominance, pleiotropy, epistasis, heterosis (positive or negative), inbreeding and other evolutionary forces such as drift and effective population size that maintain and winnow out variation have received little or no attention. Among the triumvirate (Fisher, Haldane and Wright-these are Einsteins too!-see p. 225) who brought credibility to both evolution and genetics, only Fisher is mentioned in some detail. Haldane-the 
polymath, who almost simultaneously discovered and formalized the concept of linkage (along with Morgan), mutation rate, fitness (of genotypes), selection, etc., needs to be mentioned here. Fisher extended Darwin, Galton, Johansson and Nilsen-Ehle's insights toward representing phenotypic variation as a composite of genotype and environmental variations. The author presents Fisher's way of partitioning phenotypic variation into genotypic, environmental and chance variation, but gives the impression it was Dobzhansky's. Unfortunately reference to Fisher's fundamental theorem of natural selection and its implication on genetic variation and its phenotypic expression is missing. A clear understanding of this theorem may be employed to address much of the ambiguity scattered among many pages of this book about the unpredictability of phenotypic outcome of genetic variation. Most importantly, among the three, only Sewall Wright presented consistently a dynamic view of the continuity between genotype and phenotype via development and physiology. In fact, he foresaw the central role of pleiotropy and gene combinations in development and evolution and laid the foundation for systems and network analysis in genetics and biology and now diseases, advocated in precision medicine programs. He also influenced at least four major contributors to genetics among many: Th. Dobzhansky, Jay Lush, Conrad Waddington and James Watson. Both Dobzhansky and Watson have addressed Wright as their "hero." Watson has confessed that he came across Avery's discovery of DNA while taking Wright's course on physiological genetics at the University of Chicago. It was Wright who also coined the term "epigenetics" to describe the "space" that influences the direction and distribution of gene products in development and expression of phenotypes via biochemical pathways about eight years before Waddington.

Beginning with Bateson, others such as Garrod, Bernstein, Pauling and of course Wright and Haldane were deeply interested in understanding gene action-see also Haldane (1954). Wright, however, clearly speculated the directional relationship among genes-enzymes (proteins) - phenotype as well as the influence of environment on phenotypes, at least as early as 1934. For instance, he indicated that "...the specificity in gene action is always a chemical specificity, probably the production of enzymes which guide metabolic process along particular channels," (Wright 1934a) over a decade earlier than Beadle as shown on page 163. Wright (1934b) also speculated limits to biochemical reactions which foreshadow limits to selection and perhaps limits to indiscriminate and sometimes fantastic claims about the benefits of genetic manipulation (engineering). Among these, omission of Beadle's colleague, McClintock's work is regrettable. Beadle and McClintock (1928) discovered the first functional "asynaptic" gene which affected chromosome behavior linked to phenotypic expression. Also, I believe, no history on genetics could be complete without mentioning the Ac/Ds (Activator/Dissociation system; McClintock 1950). While McClintock's imaginative work has gone unnoticed in this book, Pardee, Jacob and Monod's operon system is celebrated. Muller's work on X-ray induced mutations and his personal struggles are interesting, and so is the story about discovery of DNA structure, the greed, speed, emotions and arrogance of the players in this drama, which most geneticists are familiar with are presented well. However, following Dawkins, the author defines gene as "...a recipe that specifies an organism. The human genome is the recipe that specifies human." In doing so, he drops us squarely among sociobiologists.

Part three titled, "The Dreams of Geneticists" spreads across 1970-2001, which opened the recombinant DNA Pandora's Box, enabling manipulation of hereditary material that genes are made of. In this charming chapter, the author has explained the intricacies of cloning, recombinant DNA and the controversies that occupied the hearts and minds of "Einsteins" of molecular genetics. Besides, a few of these players were hatching the idea of harnessing the power of recombinant DNA and to establishing Genentech, which included coining a corny slogan for T-shirts to creating instant millionaires in minute details. There is a gap here. For instance, the American Society of Human Genetics was established in 1948, with Muller as its first president. Muller, Crow, Neel and others as well as their students contributed to the growth of human and medical genetics. Crow and Neel studied the effects of radiation on the Japanese. Additionally, starting from the mid-60's Lewontin, his students and Harry Harris described molecular diversity (both protein and DNA polymorphisms) in wide-ranging organisms. This discovery rescued population genetics (Charlesworth et al. 2016) and laid the foundation for new theoretical work (e.g., neutral theory, Kimura) and the growth of human genetics. This body of work has catalyzed many empirical studies toward quantifying human diversity, genome wide association studies (e.g., linkage disequilibrium), exome sequencing, next-gen sequencing and even the presentday Precision Medicine Initiative (PMI). These aside, the author has presented an excellent account of the contribution of recombinant DNA technology toward establishing a new discipline-biotechnology. He mentions that Watson characteristically mocked old time biologists as "stamp collectors" (p. 221), nonetheless he appears to be reflecting upon the value of old time biology (p. 463).

Part four, "The Proper Study of Mankind Is Man," is an appealing presentation on human genetic disorders. Here he starts off with Garrod's revolutionary work. Garrod was the first to recognize clinical and chemical 
individualities stating that, "no two individuals of a species are absolutely identical in bodily structure neither are their chemical processes carried out on exactly the same lines"- a harbinger of the PMI (Perlman and Govindaraju 2016). McKusick's contribution to the study of Mendelian genetic disorders, which has laid the foundation for medical genetics, and currently genetics of rare diseases, in the US and elsewhere, with excellent representative examples: Down syndrome, cystic fibrosis, Huntington's chorea, Tay-Sach's, Gaucher's to name a few. Nancy Wexler and her colleagues heroic efforts to find the causal gene underlying Huntington disease are well presented. While Botstein et al. clearly thought of using DNA polymorphisms to map these genes (among at least two groups of which I am aware); the original mapping algorithm was developed by Haldane (1919). But, Haldane is relegated to just over two lines on page 292 on his off-handed opinion about the impact of gene discovery. Crow, Mayr and Huxley were proponents of "responsible eugenics"-meaning couples making responsible decisions about their progeny based on their own health; something analogous to what many Jewish families have adopted in the recent years as a preventive measure to avoid Tay-Sachs and Gaucher disease. I am not convinced, however, that these three were "vociferous proponents of positive eugenics," similar to the one advocated by Davenport, Du Bois and others in the 1920s. On the contrary, James Crow in particular, was one of the most thoughtful, erudite and gentlest humanist scientist. He made fundamental contributions toward elucidating the role of mutations in genetic disorders, and therefore was aware of the pain the parents of the affected children bear, and the misery that affected children endure. He consistently maintained a voice of reason on the role of genetics in human society (Crow 1969). For example, the signatories of this view also included Dobzhansky, Emerson, Haldane, Huxley, Needham, Muller, Waddington, etc., who explicitly stated that "...there can be no valid basis for estimating and comparing the intrinsic worth of different individuals, without economic and social conditions which provide equal opportunities for all members of society..." and "race prejudices and the unscientific doctrine that good or bad genes are the monopoly of particular peoples" (Crew et al. 1939). The next three sections deal with the drama surrounding the audacious plans to sequencing the human genome, the players and their labs, soft-power diplomacy and its celebration at the Whitehouse are well presented.

Part five: "Through the Looking Glass"-in this 86-page long chapter the author goes to extra lengths to present nuances surrounding the genetic bases of intelligence, race and gender. These topics, as all of us know, are plagued with controversy and great minds in genetics have repeatedly said that looking into the genetic bases of such composite traits (many complex traits rolled into one) is an exercise in utter futility. This is precisely where evolutionary genetics knowledge is needed. The concept of heritability is central to the controversy surrounding intelligence; but heritability of any complex trait (much less a composite trait) is an ephemeral unit of measurement influenced by thousands of genes and genomic components and myriad environmental and cultural factors. Why did Lewontin express his disbelief (p. 373) over Hamer's claims? Because Lewontin was convinced how complicated it is to discover causal roots and their routes of expression of cognitive traits (Lewontin 1974; Rose 2006). Further, current genetic diversity estimates indicate that close to $95 \%$ of variation resides within populations, which supports Garrod's claims on "chemical individuality" made over a century ago and Lewontin's over 40 years ago (Lewontin 1972). Also, when it is so difficult to find causal routes of even simple traits governed by only a few genes, how could anyone find the precise genetic and environmental root causes of composite traits that follow the infinite allele model (Kimura and Crow 1964)?

- While the author has devoted much of the book to present minuscule details about molecular aspects of cloning, sequencing and the like, he pays very little attention to epigenetics. As stated earlier, genetic information flows across epigenetic space to phenotype space in relation to environment and developmental factors. Gene products will have direct, indirect, mediated, reverse, truncated and reticulated influence on the phenotype as conceived by Wright and Waddington. For instance, Waddington defined "epigenotype" as one that "consists of concatenations of processes linked together in a network, so that a disturbance at an early stage may gradually cause more and more far reaching abnormalities in many different organs and tissues" (Waddington 1942). He later defined epigenetics as "causal interactions of genes and their products which bring the phenotype into being' (Waddington 1975). Accordingly, any perturbations due to genetic, demographic and environmental factors could potentially affect the allometric relationships among physiological and morphological traits during development some of which may be expressed, even later in life. Also, imprinting disorders (e.g., Angelman and Praeder-Willi) would have served as excellent examples to illustrate the role of epigenetics in human disease. Further, Waddington's concept of canalization would be useful to evaluate and interpret "robustness" or susceptibilities of individuals to disease and environmental stresses. Insights drawn 
from epigenetics may hold promise for developing medical interventions against some developmental and metabolic disorders. Similarly, Lewontin's niche construction concept, elaborated by Feldman and his colleagues (Odling-Smee et al. 2003) would have been extremely helpful here in order to portray the malleable nature of human intelligence, including that of twins. The author informs us that, "Genes cannot tell us how to categorize or comprehend human diversity; environments can, cultures can, geographies can, histories can" (p. 349) - and they could do so only in the context of specific individuals in families and the multidimentional niche space they are part of! Evolutionary and ecological insights are therefore necessary even if we have all the sequence information from the millions. Individual phenotypes and not genes that are subjected to ecological and evolutionary forces (Hutchinson 1965).

- In part six entitled, "Post-Genome," the author writes about the successes and failures of genomic research and presents his hopes and doubts about the role of genetics in health and human welfare giving some familiar examples. These include: gene therapy study against Adenosine Deaminase deficiency (ADA), Breast Cancer (BRCA1) and schizophrenia as well as stem cell therapies. He presents the failure of gene therapy vividly, but is optimistic that "gene therapy would eventually become therapy," and quotes Church (p. 437), "every disease can be fixed by DNA." Church seems to convince us to accept the worn-out metaphor "body as a machine"-if broken, it can be fixed! While such optimism may be entertained with much reservation, the latter (every disease? note the word fixed) is a fantasy. Horizontal transfer of genes appears to be common among wide varieties of organisms, and humans are reported to have acquired nearly 150 genes from bacteria and other organisms (Williams 2015). This is only 150 genes in about 200,000 years of evolutionary history of the human genome, during which evolution must have experimented with accepting and rejecting genes from outside sources billions of times. The human genome is a co-evolved and tightly integrated system; hence it may not allow newer genes and genome fragments from unknown addresses to enter and integrate into this tightly evolved genetic community as we wish to do in clinics at will. On page 454 , he mentions the unpredictability of certain disorders using Dawkin's metaphor of blueprint and recipes. Dawkin's "selfish gene" metaphor has become another overused cliché in biology, and its applicability to real world problems have been severely contested in the last 40 years. $\mathrm{He}$ is correct in saying "the eventual effects of geneenvironment intersection can never be reliably pres- aged by the genetics alone." Yet, he states "With enough subject, and enough computational power, nearly all of the predictive capacity of the genome can, in principle, be determined." (p. 489). If we do-this will not reflect the uniqueness of the individual, but would only echo the curse of the average! On page 490, he is skeptical about altering genes, because of their plausible "butterfly effect" ... "genes may yet be more interconnected than we think." Yes, pleiotropy and gene interactions are common features in evolutionary genetics. Sewall Wright held on to these views all his life starting in 1916, and developed analytical techniques to quantify this phenomenon. New mutations could change pleiotropic influence on the genetic system, even in somatic tissues. We see such manifestation in nature all the time. Take for instance, progeria or achondroplasia, where single mutations bring about multi-compartment changes. On the other hand, single gene mutations have also contributed much to plant and animal breeding. The author didn't have to take shelter under Dawkins metaphor (which has misguided and even decelerated the growth of certain areas of genetics) to bolster his ambiguous views about the unpredictability of genetic disorders; instead he could have extended evolutionary arguments (e.g., Charlesworth and Charlesworth 2010)-demographical structure of populations (inbreeding), drift, individual variation, etc. The average individual carries numerous loss and gains of mutations, including a few lethals (Shendure and Akey 2015), and all of us are mutants in our own way (Kaiser 2014).

In sum, genetics is composed of four major facets: genotype, epigenetics (also, age and stage of development), phenotype and environment (including culture). The author gives a preferential treatment to the genomic aspect of the subject and spends over $75 \%$ of the 600 pages to it. $\mathrm{He}$ sometimes stretches a given idea or a circumstance $a d$ nauseum (oftentimes I felt that I might be reading an avatar of "The Selfish Gene" only four decades later). While the author has brought an extraordinarily important and intimate topic to the attention of the general public with his gift for narrative, he could have accomplished his objectives in half the space, with no loss to the subject he has covered. Sure, genetics in just over 110 years has given us incredible insights into our biological world, but it has also showed us its and our own limitations.

There is a story in the Chandogya Upanishad, in which a father asks his son to break open a fig. The father then asks his son, "what do you see?". The son replies, "seeds sir". The father asks him again to open a few of the seeds; which he does. The father questions his son again, "What do you see, now?" Son replies "nothing Sir." Father smiles and says..."that is the essence." Is it? 
To quote Lewontin (1974), "The significance of the transformation of our problem from a micro- to a macrodescription does not lie only in what can be measured, but also in what exists...Genes in populations do not exist in random combination with other genes. The alleles at a locus are segregating in a context that includes a great deal of correlation with the segregation of other genes at nearby loci. The fitness at a single locus ripped from its interactive context is about as relevant to real problems of evolutionary genetics as the study of the psychology of individuals isolated from their social context is to an understanding of man's sociopolitical evolution. In both cases context and interaction are not simply secondorder effects to be superimposed on a primary monadic analysis. Context and interaction are of the essence."

\section{Author details}

${ }^{1}$ Department of Human Evolutionary Biology, Harvard University, 11 Divinity Avenue, Cambridge, MA 02130, USA. ${ }^{2}$ The Institute for Aging Research, Albert Einstein College of Medicine, 1300 Morris Park Avenue, Bronx, NY 10461, USA.

\section{Competing interests}

The author declares that he has no competing interests.

Received: 15 November 2016 Accepted: 20 November 2016

Published online: 06 December 2016

\section{References}

Beadle GA, McClintock B. A genic disturbance of meiosis in Zea mays. Science. 1928;68:433.

Charlesworth B, Charlesworth D. Elements of evolutionary genetics. Greenwood Village: Roberts \& Co.; 2010.

Charlesworth B, Charlesworth D, Coyne JA, Langley CH. Hubby and Lewontin on protein variation in natural populations: when molecular genetics came to the rescue of population genetics. Genetics. 2016;203:1497-503.
Crew FAE, Darlington CD, Haldane JBS, Harland SC, et al. Social biology and population improvement. Nature. 1939;144:521-2.

Crow JF. Genetic theories and influences: comments on the value of diversity. Harv Educ Rev. 1969;39:153-61.

Haldane JBS. The combination of linkage values, and the calculation of distances between the loci of linked factors. J Genet. 1919;8:299-309.

Haldane JBS. The biochemistry of genetics. London: Allen \& Unwin; 1954

Hutchinson GE. The ecological theater and evolutionary play. New Haven: Yale University Press; 1965

Huxley J. Evolution: the modern synthesis. New York: Harper; 1942.

Kaiser J. The hunt for missing genes. Science. 2014:344:688-9.

Kimura M, Crow J. The number of alleles that can be maintained in a finite population. Genetics. 1964;49:725-38.

Lewontin RC. The apportionment of human diversity. Evol Biol. 1972;6:381-98.

Lewontin RC. The genetic bases of evolutionary change. New York: Columbia University Press; 1974a.

Lewontin RC. The analysis of variance and the analysis of causes. Am J Hum Genet. 1974b:26:400-11.

Lewontin RC. Foreword to the character concept in evolutionary biology. In: Wagner GP, editor. Cambridge: Academic Press; 2001. p. 17-23.

McClintock B. The origin and behavior of mutable loci in maize. Proc Natl Acad Sci. 1950:36:344-55.

Odling-Smee FJ, Laland K, Feldman MW. Niche construction: the neglected process in evolution. Princeton: Princeton University Press; 2003.

Perlman RL, Govindaraju DR. Archibald E. Garrod: the father of Precision Medicine. Genet Med. 2016;18:1088-9.

Provine WB. Sewall Wright and evolutionary biology. Chicago: The University of Chicago Press; 1986. (Wright S. Sewall Wright's letter to Paul Popenoe in 1931 on the marginal and contextual role of gene in eugenics).

Rose SPR. Commentary: heritability estimates-long past their sell-by date. Int J Epidemiol. 2006:35:525-7.

Shendure J, Akey JM. The origins, determinants, and consequences of human mutations. Science. 2015:349:1478-83.

Waddington CH. The epigenotype. Endeavour. 1942;1:18-21.

Waddington $\mathrm{CH}$. The evolution of an evolutionist. Ithaca: Cornell University Press; 1975.

Williams SCP. Humans may harbor more than 100 genes from other organisms. Science. 2015:347:1478-83.

Wright S. Genetics of abnormal growth in the guinea pig. In: Cold Spring Harbor symposium on quantitative biology, vol 2. New York: Cold Spring Harbor Laboratory Press; 1934a. p. 142.

Wright S. Physiological and evolutionary theories of dominance. Am Nat. 1934b;68:25-53.

\section{Submit your manuscript to a SpringerOpen ${ }^{\circ}$ journal and benefit from:}

- Convenient online submission

- Rigorous peer review

- Immediate publication on acceptance

- Open access: articles freely available online

- High visibility within the field

- Retaining the copyright to your article

Submit your next manuscript at springeropen.com 